\title{
PERAN EKUITAS MERK TERHADAP LOYALITAS MERK BARBERSHOP DI KOTA YOGYAKARTA
}

\author{
Budi Setyanta \\ Fakultas Ekonomi Universitas Janabadra Yogyakarta \\ Email: setyantabudi@gmail.com
}

\begin{abstract}
This study aims to identify the role of brand equity on brand loyalty in the barbershop. 200 samples were collected using questionnaires to test multiple linear regression using SPSS tool. The results of this study indicate that the dimension of brand equity has a positive and significant effect on brand loyalty barbershop. Further research is needed to test the model of this study to examine the model's generalisation capabilities.
\end{abstract}

Keywords: Brand Loyalty, Brand Equity

\section{ABSTRAK}

Penelitian ini bertujuan untuk mengidentifikasi peran ekuitas merk terhadap loyalitas merk pada barbershop. Sampel berjumlah 200 dikumpulkan dengan menggunakan kuesioner untuk diuji regresi linier berganda dengan menggunakan alat SPSS. Hasil penelitian ini menunjukan bahwa dimensi ekuitas merk berpengaruh positif dan signifikan terhadap loyalitas merk barbershop. Penelitian selanjutnya diperlukan untuk menguji model penelitian ini untuk menguji kemampuan generaliisasi model.

Kata kunci: Loyalitas merk, Ekuitas Merk

\section{PENDAHULUAN}

Perkembangan teknologi berdampak pada mudahnya produsen menawarkan produk yang mengakibatkan meningkatnya keragaman produk dengan kualitas yang terstandarisasi, sehingga konsumen mengalami kesulitan dalam membedakan produk berdasarkan kualitasnya.
Salah satu cara konsumen dalam membedakan suatu produk dari pesaing adalah melalui merk (Aaker, 2014:42), karena merk memudahkan konsumen dalam mencari, mengevaluasi dan memutuskan pembelian suatu produk atau jasa. Merk merupakan aset berharga bagi perusahaan, karena dapat memiliki nilai lebih besar dari aset fisik perusahaan. 
Merk berpengaruh terhadap keunggulan bersaing karena dapat meningkatkan komunikasi pemasaran, perluasan merk, loyalitas pelanggan dan keuntungan perusahaan, hal tersebut mendorong produsen untuk membangun merk yang kuat. Kemampuan untuk mengidentifikasi faktor-faktor yang mempengaruhi kekuatan merk merupakan hal utama dalam membangun merk. Salah satu faktor yang berpengaruh terhadap kekuatan merk adalah ekuitas merk (Keller, 2009:63).

Ekuitas merk mempengaruhi diferensiasi produk karena semakin tinggi ekuitas merk maka semakin mudah dibedakan dengan produk pesaing., sehingga merupakan merk yang pertama kali diingat dan dipertimbangkan dalam melakukan pembelian maupun menjadi merk yang direkomendasikan kepada orang lain. Ekuitas merk yang tingi dapat meningkatkan keuntungan perusahaan karena dipersepsikan sebagai produk yang lebih baik dibanding pesaing sehingga pelanggan rela membayar lebih tinggi dibanding harga pesaing.

Ekuitas merk terdirti dari kesadaran merk, asosiasi merk, kualitas yang dirasakan, loyalitas merk, dan aset lainnya yang dapat mengurangi atau menambah nilai merk (Aaker, 1991).

Pemahaman perusahaan terhadap ekuitas merk dari sudut pandang pelanggan akan meningkatkan keuntungan perusahaan karena pelanggan rela membayar lebih mahal produk yang memiliki ekuitas tinggi, mencari saluran distribusi yang baru, memudahkan komunikasi pemasaran, perluasan merk dan lisensi dagang (Keller, 1993)

Ekuitas merek berpengaruh positif terhadap perilaku pembelian karena dapat meningkatkan loyalitas merk (Kim dan Hyun, 2011). Loyalitas merk ditunjukan kedekatan hubungan dengan pelanggan, pembelian ulang, pelanggan tidak terlalu sensitif terhadap kenaikan harga, memberikan rekomendasi kepada orang lain serta tidak terpengaruh iklan produk pesaing (Meyer dan Blümelhuber, 2000).

Penelitian ini bertujuan untuk mengidentifikasi pengaruh ekuitas merk terhadap loyalitas pada barbershop di Kota Yogyakarta. Pertumbuhan usaha barbershop di Kota Yogyakarta sangat pesat, baik 
usaha perorangan maupun waralaba. Setiap barbershop memiliki merk berbeda sehingga memudahkan pelanggan untuk memilih dan membandingkan persepsi manfaat yang diberikan oleh masing-masing barbershop (Setyanta, 2017)

Barbershop perlu mengukur ekuitas merknya untuk mengetahui kekuatannya dibandingkan pesaing sehingga dapat digunakan sebagai dasar dalam mengembangkan strategi pemasaran. Indikator ekuitas merk dalam penelitian ini adalah kualitas fisik, perilaku staff, ideal selfcongruence, identifikasi merek dan lifestyle-congruence ( $\mathrm{Nam}$ et al, 2011).

Kualitas fisik merupakan persepsi pelanggan terhadap desain, fasilitas, peralatan, bangunan. Perilaku staff ditunjukan oleh kompetensi, keahlian, kesopanan, keramahan karyawan. ideal self-congruence merupakan keseluruhan pikiran dan perasaan seseorang dengan mengacu pada orang tersebut sebagai objek pemikiran. Ideal self-congruence mengacu pada sejauh mana konsep aktual dan ideal konsumen yang sesuai dengan citra merk, sehingga orang membeli atau memiliki suatu merk digunakan untuk mempertahankan atau meningkatkan harga diri mereka. Identitas merk merupakan kemampuan merk untuk mendukung konsumen menunjukan identitas sosialnya pada kelompok masyarakat. Lifestyle-congruence merupakan kemampuan merk untk mendukung gaya hidup konsumen dengan menggunakan konsep diri dan kelompok sosial sebagai standar perbandingan.

\section{METODE PENELITIAN}

Ketaatan dalam mengembangkan metode penelitian adalah penting karena mempengaruhi kualitas penelitian. Metode penelitian terdiri dari desain pengambilan sampel, pengukuran dan analisis data (Sekaran dan Bougie, 2013). Penelitian ini menjelaskan hubungan sebab akibat antara ekuitas merk dengan variabel loyalitas pelanggan.

Survey pada penelitian ini menggunakan kuesioner dengan skala likert dari angka 1 = sangat tidak setuju sampai dengan angka $5=$ sangat setuju. Dan agar jumlah sampel yang diperoleh memenuhi syarat yang ditentukan maka untuk meningkatkan respon rate, responden dalam 
mengisi kuesioner ditunggu sampai selesai menjawab pertanyaan.

Populasi dalam penelitian ini adalah masyarakat Yogyakarta yang pernah menggunakan jasa barbershop. Penelitian ini menggunakan sampel sebanyak 200 untuk memenuhi syarat uji SEM (Loehlin et al., 1998).

Karena penelitian ini hanya dilakukan pada periode tertentu dan hasil penelitian ini tidak dapat menjawab loyalitas pelanggan pada periode lainnya, maka penelitian ini dikategorikan sebagai penelitian cross-sectional.

\section{HASIL DAN PEMBAHASAN}

Uji terhadap kualitas data perlu dilakukan untuk menjamin terpenuhinya asumsi untuk melakukan uji regresi berganda.

\section{Uji Validitas}

Uji validitas digunakan untuk mengidentifikasi valid tidaknya suatu kuesioner. Kemampuan item dalam kuesioner dalam menjawab fenomena loyalitas merk barbershop menjukan data penelitian valid.

Uji signifikasi validitas data dengan membandingkan nilai $r$ hitung dengan $r$ tabel, jika $r$ hitung > r tabel maka data penelitian dikatakan valid, begitupula sebaliknya.

Hasil uji validitas data penelitian menunjukan bahwa semua data penelitian valid, sehingga data penelitian layak digunakan, dan dilakukan uji statistik berikutnya.

Tabel 1 Hasil Uji Validitas

\begin{tabular}{|l|c|c|c|}
\hline & $\begin{array}{c}\mathbf{r} \\
\text { Hitung }\end{array}$ & $\begin{array}{c}\mathbf{r} \\
\text { tabel }\end{array}$ & $\begin{array}{c}\text { Keteranga } \\
\mathbf{n}\end{array}$ \\
\hline $\begin{array}{l}\text { KUALITAS } \\
1\end{array}$ & 0.566 & 0.266 & VALID \\
\hline $\begin{array}{l}\text { KUALITAS } \\
2\end{array}$ & 0.757 & 0.266 & VALID \\
\hline $\begin{array}{l}\text { KUALITAS } \\
3\end{array}$ & 0.643 & 0.266 & VALID \\
\hline $\begin{array}{l}\text { KUALITAS } \\
4\end{array}$ & 0.635 & 0.266 & VALID \\
\hline $\begin{array}{l}\text { KUALITAS } \\
5\end{array}$ & 0.613 & 0.266 & VALID \\
\hline $\begin{array}{l}\text { PERILAKU } \\
1\end{array}$ & 0.664 & 0.266 & VALID \\
\hline $\begin{array}{l}\text { PERILAKU } \\
2\end{array}$ & 0.672 & 0.266 & VALID \\
\hline $\begin{array}{l}\text { PERILAKU } \\
3\end{array}$ & 0.595 & 0.266 & VALID \\
\hline $\begin{array}{l}\text { PERILAKU } \\
4\end{array}$ & 0.533 & 0.266 & VALID \\
\hline $\begin{array}{l}\text { PERILAKU } \\
5\end{array}$ & 0.522 & 0.266 & VALID \\
\hline IDEAL1 & 0.567 & 0.266 & VALID \\
\hline IDEAL2 & 0.575 & 0.266 & VALID \\
\hline IDEAL3 & 0.506 & 0.266 & VALID \\
\hline IDEAL4 & 0.614 & 0.266 & VALID \\
\hline IDEAL5 & 0.652 & 0.266 & VALID \\
\hline IDENT1 & 0.525 & 0.266 & VALID \\
\hline IDENT2 & 0.551 & 0.266 & VALID \\
\hline IDENT3 & 0.593 & 0.266 & VALID \\
\hline IDENT4 & 0.685 & 0.266 & VALID \\
\hline IDENT5 & 0.652 & 0.266 & VALID \\
\hline LIFE1 & 0.604 & 0.266 & VALID \\
\hline LIFE2 & 0.678 & 0.266 & VALID \\
\hline LIFE3 & 0.611 & 0.266 & VALID \\
\hline LIFE4 & 0.678 & VALID \\
\hline IFE5 & 0.266 & VALID \\
\hline
\end{tabular}




\begin{tabular}{|l|r|r|c|} 
& & 0.26 & \\
LOYAL1 & 0.623 & 6 & VALID \\
\hline LOYAL2 & 0.669 & 0.266 & VALID \\
\hline LOYAL3 & 0.674 & 0.266 & VALID \\
\hline LOYAL4 & 0.528 & 0.266 & VALID \\
\hline LOYAL5 & 0.572 & 0.266 & VALID \\
\hline
\end{tabular}

Sumber: Data Primer

\section{Uji Reliabilitas}

Reliabilitas kuesioner terjadi jika terdapat konsistensi jawaban terhadap pertanyaan adalah dari waktu ke waktu.

Tabel 2

Hasil Uji Reliabilitas

\begin{tabular}{|l|r|}
\hline & \multicolumn{1}{|c|}{ Cronbach's Alpha } \\
\hline KUALITAS & 0.823 \\
\hline PERILAKU & 0.851 \\
\hline IDEAL & 0.882 \\
\hline IDENTITAS & 0.901 \\
\hline LIFE & 0.875 \\
\hline LOYALITAS & 0.862 \\
\hline \multicolumn{2}{|c|}{ Sumber: Data Primer }
\end{tabular}

Hasil uji data penelitian menunjukan bahwa nilai Cronbach's Alpha semua variabel penelitian > 0,7, hal ini memiliki kesimpulan bahwa kuesioner penelitian adalah reliabel atau handal karena jawaban responden terhadap pertanyaan kuesioner penelitian adalah konsisten dari waktu ke waktu, sehingga dapat dilakukan uji selanjutnya.

\section{Uji Normalitas}

Uji normalitas diperlukan untuk memastikan bahwa variabel pengganggu atau residual data berdistribusi normal untuk memenuhi asumsi syarat uji $\mathrm{t}$ dan $\mathrm{F}$ sehingga jika data tidak normal maka penelitian dikatakan tidak valid

Deteksi uji normalitas dapat dilakukan dengan analisis grafik maupun uji statistik. Penelitian ini untuk menguji normalitas data digunakan Kolmogorov-Smirnov Test, sehingga data dikatakan normal jika nilai signifikansi $>0,05$

Tabel 3

Hasil Uji Normalitas

\begin{tabular}{|ll|r|}
\hline & & $\begin{array}{r}\text { Unstandardize } \\
\text { d Residual }\end{array}$ \\
\hline $\mathrm{N}$ & & 200 \\
Normal & Mean & .0000000 \\
Parameters & a & Std. \\
b & Deviatio & 3.55607631 \\
& $\mathrm{n}$ & \\
Most & Absolute & .082 \\
Extreme & Positive & .074 \\
Differences & Negative & -.073 \\
Kolmogorov-Smirnov & .583 \\
Z & & \\
Asymp. Sig. (2-tailed) & .746 \\
\hline
\end{tabular}

Sumber: Data Primer

Data penelitian dapat dikatakan berdistribusi normal karena nilai 
Kolmogorov-Smirnov adalah sebesar 0,746 dan lebih besar dari 0,05.

\section{Uji Multikolinieritas}

Multikolinieritas adalah ukuran yang menunjukkan apakah suatu variabel independen dijelaskan oleh variabel independen yang lain. Gejala multikolinearitas pada model penelitian dapat diidentifikasi dari nilai Tolerance dan Variance Inflation Factor (VIF).

Tolerance mengukur variabilitas variabel independen yang terpilih yang tidak dijelaskan oleh variabel independen lainnya. Jadi nilai tolerance yang tinggi sama dengan nilai VIF tinggi (karena $\mathrm{VIF}=1 /$ Tolerance). Nilai cutoff yang umum dipakai untuk menunjukkan adanya multikolinearitas adalah nilai Tolerance $\leq 0.10$ atau sama dengan nilai VIF $\geq 10$ dengan tingkat kolonieritas 0.95

Hasil uji multikolinieritas dapat dilihat dari nilai Tolerance dan Variance Inflation Factor (VIF).

Nilai yang umum dipakai untuk menunjukkan adanya multikolinearitas adalah nilai Tolerance $\leq$ 0.10 atau sama dengan nilai VIF $\geq$ 10 pada tingkat kolonieritas 0.95 .
Tabel 4 Hasil Uji Multikolinieritas

\begin{tabular}{|l|r|r|}
\hline \multirow{2}{*}{} & \multicolumn{2}{|c|}{ Collinearity Statistics } \\
\cline { 2 - 3 } & Tolerance & VIF \\
\hline KUALITAS & .822 & 1.216 \\
\hline PERILAKU & .408 & 2.448 \\
\hline IDEAL & .410 & 2.437 \\
\hline IDENTITAS & .888 & 1.126 \\
\hline LIFE & .700 & 1.428 \\
\hline \multicolumn{2}{|c|}{ Sumber: Data Primer }
\end{tabular}

Dari uji statistik multikolinieritas diketahui bahwa nilai tolerance $>0,1$ dan nilai VIF $<10$ untuk semua variabel penelitian, sehingga data penelitian tidak mengalami multikolinieritas, dan dapat digunakan untuk uji statistik berikutnya.

\section{Uji Heterokedastisitas}

Tabel 5 Hasil Uji Heterokedastisitas

\begin{tabular}{|l|r|}
\hline \multicolumn{2}{|c|}{ Coefficients $^{\mathbf{a}}$} \\
\hline Model & \multicolumn{1}{|c|}{ Sig. } \\
\hline KUALITASt) & 0 \\
\hline PERILAKU & 0.051 \\
\hline IDEAL & 0.672 \\
\hline IDENTITAS & 0.095 \\
\hline LIFE & 0.082 \\
\hline
\end{tabular}

a. Dependent Variable: RES2

Sumber: Data Primer

Untuk mendeteksi keberadaan adanya heteroskedastisitas dilakukan dengan metode Glejser Test, yaitu dengan cara meregresikan nilai absolute residual terhadap variabel inde- 
penden, sehingga dapat diketahui ada tidaknya derajat kepercayaan $5 \%$. Jika nilai signifikansi variabel independen >0,05 maka tidak terjadi heteroskedastisitas. Sebaliknya, jika nilai signifikansi variabel independen $<0,05$ maka terjadi heteroskedastisitas.

Hasil uji statistik dengan metode uji glejser diketahui bahwa nilai signifikansi semua variabel independen $>0,05$, sehingga tidak terjadi heterokedastisitas, dan dapat dilanjutkan uji statistik berikutnya.

\section{Uji Autokorelasi}

\section{Tabel 6 Hasil Uji Autokorelasi}

\begin{tabular}{|c|c|c|}
\hline $\begin{array}{c}\text { Adjusted R } \\
\text { Square }\end{array}$ & $\begin{array}{c}\text { Std. Error of } \\
\text { the Estimate }\end{array}$ & $\begin{array}{c}\text { Durbin- } \\
\text { Watson }\end{array}$ \\
\hline 0.64 & 4.002 & 1.973 \\
\hline
\end{tabular}

Sumber: Data Primer

Autokorelasi merupakan terjadinya antar amatan (observasi), baik dalam penelitian deret waktu (time series) maupun cross-section. Akibat dari autokorelasi adalah sebagai berikut:

- Hasil uji statistik menjadi tidak efisien (tidak lagi mempunyai varians minimum)

- Uji t dan uji F tidak lagi sah, dan jika diterapkan dapat memberikan kesimpulan yang menyesatkan mengenai arti statistik dari koefisien regresi yang ditaksir.

- Hasil uji statistik memberikan gambaran yang menyimpang dari nilai populasi yang sebenarnya. Dengan kata lain, penaksir menjadi sensitif terhadap fluktuasi penyampelan.

Uji autokorelasi dilakukan dengan metode Durbin-Watson. Jika nilai Durbin-Watson berkisar antara nilai batas atas $(\mathrm{du})$ maka diperkirakan tidak terjadi autokorelasi. Dasar pengambilan keputusan uji autokorelasi adalah sebagai berikut:

- Bila angka DW < dl, berarti ada autokorelasi positif

- $\quad$ Bila angka DW terletak antara $\mathrm{dl} \leq \mathrm{dw} \leq \mathrm{du}$, berarti tidak ada kesimpulan

- $\quad$ Bila angka DW terletak antara $\mathrm{du} \leq \mathrm{dw} \leq 4-\mathrm{du}$, berarti tidak ada autokorelasi (korelasi positif maupun negatif).

- $\quad$ Bila angka DW terletak antara $4-\mathrm{du} \leq \mathrm{dw} \leq \mathrm{du}$, berarti tidak ada kesimpulan.

- Bila angka DW > $4-\mathrm{dl}$, berarti ada autokorelasi negatif. 
Hasi uji statistik diketahui bahwa nilai Durbin-Watson sebesar 1,973, sehingga nilai 1,928 berada diantara $\mathrm{du} \leq \mathrm{dw} \leq 4-\mathrm{du}$, atau $1,7071 \leq 1,973 \leq 4-1,8306$, hal itu menunjukan bahwa data penelitian menurut kriteria berarti tidak mengalami autokorelasi.

\section{Uji Hipotesis}

Tabel 7 Hasil Uji Regresi Linier

\begin{tabular}{|l|c|c|r|}
\hline & \multicolumn{3}{|c}{ Berganda } \\
& $\begin{array}{l}\text { Standardized } \\
\text { Coefficients }\end{array}$ & $\mathrm{t}$ & Sig. \\
\hline (Constant) & 0.332 & 2.114 & 0.026 \\
\hline KUALITAS & 0.013 & 2.064 & 0.021 \\
\hline PERILAKU & 0.221 & 2.122 & 0.037 \\
\hline IDEAL & 0.035 & 3.015 & 0.019 \\
\hline IDENTITAS & 0.426 & 2.097 & 0.031 \\
\hline LIFE & & & \\
\hline
\end{tabular}

Sumber: Data Primer

\section{Uji F}

Tabel 8 Nilai F Hitung

\begin{tabular}{|l|r|r|r|r|r|}
\hline & $\begin{array}{r}\text { Sum of } \\
\text { Squares }\end{array}$ & df & $\begin{array}{r}\text { Mean } \\
\text { Square }\end{array}$ & F & Sig. \\
\hline Regression & 182.254 & 5 & 27.337 & 2.657 & .034 \\
\hline Residual & 713.486 & 194 & 14.864 & & \\
\hline Total & 910.981 & 199 & & & \\
\hline
\end{tabular}

Sumber: Data Primer

Uji statistik F untuk mengidentifikasi apakah model penelitian fit dan mampu menjawab permasalahan penelitian berdasarkan teori-teori dan bukti empiris yang digunakan dalam mengembangkan model penelitian. Pengujian dilakukan dengan meng- gunakan tingkat signifikansi 0,05 $(\alpha=5 \%)$.

Pada penelitian ini digunakan sampel penelitian sebanyak 200 responden dan enam variabel, sehingga $\mathrm{df}_{1}$ sebanyak 6-1 = 5 dan $\mathrm{df}_{2}$ sebanyak 200-6 = 194. Dari data tersebut maka dari tabel distribusi $\mathrm{F}$ diketahui nilai $\mathrm{F}$ tabel pada $\mathrm{F}_{(6 ; 194)}$ adalah sebesar 2,26. Model penelitian dikatakan fit jika nilai $\mathrm{F}$ hitung $>$ f tabel.

Nilai F hitung sebesar 2,657 dan lebih besar dari nilai $\mathrm{F}$ tabel yaitu sebesar 2,26. Kemudian nilai signifikasni diketahui sebesar 0,034 dan lebih kecil dari 0,05. Hal menunjukan bahwa variabel independen model penelitian ini fit sehingga model penelitian ini termasuk baik dan mampu menjawab permsalahan penelitian.

\section{Uji Hipotesis Pertama}

H1 : Kualitas fisik berpengaruh positif dan signifikan terhadap loyalitas pada barbershop

Hasil uji regresi linier berganda menunjukan bahwa koefisien variabel kualitas fisik adalah 0,332 dengan nilai t hitung sebesar 2,114> 
1,872, atau nilai t hitung lebih besar dari nilai t tabel. Kemudian nilai signifikansi variabel keandalan sebesar $0,026<0,05$. Hasil uji statistik itu menunjukan bahwa variabel kualitas fisik berpengaruh positif dan signifikan terhadap kepuasan pelanggan. Hasil uji statistik tersebut menunjukan bahwa hipotesis 1 dalam penelitian ini didukung. Hasil penelitian itu menunjukan bahwa jika kualitas bangunan, ruang tunggu, toilet, kualitas shower dan peralatan cukur semakin baik maka loyalitas pelanggan semakin tinggi.

Hasil penelitian ini tidak sejalan dengan penelitian Nam et al (2011), yang mengidentifikasi bahwa kualitas fisik berpengaruh secara tidak langsung terhadap loyalitas karena dimediasi oleh kepuasan pelanggan. Perbedaan hasil tersebut dapat diakibatkan karena model penelitian ini tidak menggunakan variabel mediasi kepuasan pelanggan sehingga peran mediasi diabaikan dalam penelitian ini. Perbedaan hasil kemungkinan dikarenakan adanya perbedaan setting dan subyek penelitian sehingga preferensi sampel terhadap subyek penelitian mengalami perbedaan.
Karena ada keragaman perbedaan maka model penelitian ini perlu diuji pada setting dan subyek penelitian berbeda untuk menguji generalisasi model penelitian.

\section{Uji Hipotesis Kedua}

H2 : Perilaku staff berpengaruh positif dan signifikan terhadap terhadap loyalitas pada barbershop

Hasil uji regresi linier berganda menunjukan bahwa koefisien variabel perilaku staff adalah 0,013 dengan nilai t hitung sebesar 2,0640 $>1,872$, atau nilai $\mathrm{t}$ hitung lebih besar dari nilai $\mathrm{t}$ tabel, kemudian nilai signifikansi variabel perilaku staff sebesar 0,021 < 0,05. Hasil uji statistik tersebut menunjukan bahwa jika karyawan semakin ramah, semakin cepat merespon keluhan pelanggan, mampu memberikan solusi bagi pelanggan, karyawan semakin sopan, dan semakin tanggap kebutuhan pelanggan, maka akan meningkatkan loyalitas pelanggan. Hasil uji statistik tersebut menunjukan bahwa hipotesis 2 dalam penelitian ini didukung.

Penelitian ini sejalan dengan penelitian yang dilakukan oleh Nam et al (2011) yang mengidentifikasi 
bahwa perilaku staff berpengaruh secara langsung terhadap loyalitas pelanggan. Hal ini menunjukan konsistensi positif dan signifikan pengaruh perilaku staff terhadap loyalitas pelanggan.

Meskipun hasil ini sejalan dengan penelitian sebelumnya, tetapi model penelitian ini perlu diuji pada setting dan subyek penelitain yang berbeda untuk menguji generalisasi model penelitian, karena model penelitian akan semakin baik jika mampu digunakan pada beragam setting dan subyek penelitian.

\section{Uji Hipotesis Ketiga}

H3 : ideal self-congruence ber pengaruh positif dan signifikan terhadap terhadap loyalitas pada barbershop

Hasil uji regresi linier berganda menunjukan bahwa koefisien variabel ideal self-congruence adalah 0,221 dengan nilai t hitung sebesar $2,122>1,872$, atau nilai $\mathrm{t}$ hitung lebih besar dari nilai t tabel, kemudian nilai signifikansi variabel bukti fisik sebesar 0,037 < 0,05. Hasil uji statistik tersebut menunjukan bahwa identitas barbershop sesuai harapan saya, barbershop konsisten seperti harapan saya, barbershop membuat saya bangga, barbershop mewakili kepribadian saya, barbershop membuat saya bahagia berpengaruh positif dan signifikan terhadap kepuasan pelanggan. Hasil uji statistik tersebut menunjukan bahwa hipotesis 3 dalam penelitian ini didukung.

Penelitian ini sejalan dengan penelitian yang dilakukan oleh Nam et al (2011) yang mengidentifikasi bahwa ideal self-congruence berpengaruh secara langsung terhadap loyalitas pelanggan. Hal ini menunjukan konsistensi positif dan signifikan pengaruh ideal self-congruence terhadap loyalitas pelanggan.

Meskipun hasil ini sejalan dengan penelitian sebelumnya, tetapi model penelitian ini perlu diuji pada setting dan subyek penelitain yang berbeda untuk menguji generalisasi model penelitian, karena model penelitian akan semakin baik jika mampu digunakan pada beragam setting dan subyek penelitian.

\section{Uji Hipotesis Keempat}

H4 : Identitas merk berpengaruh positif dan signifikan terhadap loyalitas pada barbershop 
Hasil uji regresi linier berganda menunjukan bahwa koefisien variabel identitas merk adalah 0,035 dengan nilai t hitung sebesar 3,015> 1,872, atau nilai $\mathrm{t}$ hitung lebih besar dari nilai t tabel, dan nilai signifikansi variabel empati sebesar 0,019 $<0,05$. Hasil uji statistik tersebut menunjukan nama barbershop yang menarik, logo barbershop menarik, nama barbershop menunjukan kesan modern, nama barbershop menjadi trendsetter, nama barbershop mencerminkan kesuksesan berpengaruh positif dan signifikan terhadap loyalitas pelanggan. Hasil uji statistik tersebut menunjukan bahwa hipotesis 4 dalam penelitian ini didukung.

Penelitian ini sejalan dengan penelitian yang dilakukan oleh Nam et al (2011) yang mengidentifikasi bahwa identitas merk berpengaruh secara langsung terhadap loyalitas pelanggan. Hal ini menunjukan konsistensi positif dan signifikan pengaruh Identitas merk terhadap loyalitas pelanggan.

Meskipun hasil ini sejalan dengan penelitian sebelumnya, tetapi model penelitian ini perlu diuji pada setting dan subyek penelitain yang berbeda untuk menguji generalisasi model penelitian, karena model penelitian akan semakin baik jika mampu digunakan pada beragam setting dan subyek penelitian.

\section{Uji Hipotesis lima}

H5 : Lifestyle-congruence berpengaruh positif dan signifikan terhadap terhadap loyalitas pada barbershop.

Hasil uji regresi linier berganda menunjukan bahwa koefisien variabel Lifestyle-congruence adalah 0,426 dengan nilai t hitung sebesar 2,097 > 1,872, atau nilai $\mathrm{t}$ hitung lebih besar dari nilai t tabel, dan nilai signifikansi variabel daya tanggap sebesar 0,031<0,05. Hasil uji statistik tersebut menunjukan bahwa barbershop mendukung gaya hidup, barbershop sejalan dengan gaya hidup, potong ranbut di barbershop mendukung gaya hidup, potong rambut di barbershop memperkuat gaya hidup, potong rambut di barbershop sesuai dengan gaya hidup berpengaruh positif dan signifikan terhadap kepuasan pelanggan. Hasil uji statistik tersebut menunjukkan bahwa hipotesis 5 dalam penelitian ini didukung.

Hasil penelitian ini tidak sejalan dengan penelitian Nam et al 
(2011), yang mengidentifikasi bahwa

Lifestyle-congruence berpengaruh secara tidak langsung terhadap loyalitas karena dimediasi oleh kepuasan pelanggan. Perbedaan hasil tersebut dapat diakibatkan karena model penelitian ini tidak menggunakan variabel mediasi kepuasan pelanggan sehingga peran mediasi diabaikan dalam penelitian ini. Perbedaan hasil kemungkinan dikarenakan adanya perbedaan setting dan subyek penelitian sehingga preferensi sampel terhadap subyek penelitian mengalami perbedaan.

Karena ada keragaman perbedaan maka model penelitian ini perlu diuji pada setting dan subyek penelitian berbeda untuk menguji generalisasi model penelitian.

\section{Uji Koefisien Determinasi}

Tabel 9 Nilai Koefisien

\section{Determinasi}

\begin{tabular}{|c|r|r|r|}
\hline $\mathrm{R}$ & \multicolumn{1}{|c|}{$\begin{array}{c}\mathrm{R} \\
\text { Square }\end{array}$} & $\begin{array}{c}\text { Adjusted } \\
\text { R Square }\end{array}$ & $\begin{array}{r}\text { Std. Error of } \\
\text { the Estimate }\end{array}$ \\
\hline .652 & .668 & .61 & 2.98542 \\
\hline
\end{tabular}

Sumber: Data Primer

$$
\begin{aligned}
& \text { Nilai Adjusted } R \text { Square } \\
& \text { sebesar 0,61 menunjukan bahwa } \\
& \text { variabel independen dalam peneltian } \\
& \text { ini memberikan kontribusi terhadap }
\end{aligned}
$$

kepuasan pelanggan sebesar $61 \%$ sedangkan 39\% dijelaskan oleh variabel lain di luar variabel-variabel yang digunakan dalam penelitian ini.

\section{SIMPULAN}

Merk merupakan aset berharga perusahaan karena meudahkan pelanggan membedakan dengan pesaing. Kekuatan merk memberikan kontribusi yang menguntungkan bagi perusahaan karena dapat meningkatkan pendapatan, karena menjamin pembelian ulang yang lebih banyak oleh pelanggan.

Kemampuan perusahaan dalam mengembangkan merk menjadi hal yang sangat penting karena penelitian ini mengidentifikasi bahwa semua dimensi ekuitas merk berpengaruh positif dan signifikan terhadap loyalitas merk.

Penelitian selanjutnya untuk menguji generalisasi model dapat dilakukan pada setting berbeda maupun untuk penelitian diluar barbershop.

\section{DAFTAR RUJUKAN}

Aaker, D. (2014). Building Strong Brands.Terjemahan oleh A. Baderi, Jakarta: Bumi Aksara. 
Kevin Lane Keller., 2003, Strategic Brand Manajemen, Second Edition, NY. Prentice Hall

Kim, J. H., \& Hyun, Y. J. (2011). A model to investigate the influence of marketing- mix efforts and corporate image on brand equity in the IT software sector. Industrial Marketing Management, 40(3), 424-438.

Meyer, A., \& Blümelhuber, C. (2000). Relationship marketing success through investments in services. In Hennig-Thurau, T. \& Hansen, U. (Eds.), Relationship marketing:Gaining Competitive Advantage through Customer Satisfaction and Customer Retention (pp. 107126). Berlin: Springer.

Setyanta, Budi. (2017). Anteseden dan Konsekuensi dari Kepuasan Pelanggan: Survei Kepuasan Pelanggan Barbershop $d i$ Yogyakarta. Al Tijarah,3(1):2944.

Nam, J., Ekinci, Y., Whyatt, G. (2011). Brand Equity, Brand Loyalty, and Consumer Satisfaction. Annals of Tourism Research, 38(3): 1009-1030.

Sekaran, U. and Bougie, R., (2013). Research Method for Business A Skill building Approach, $^{\text {th }}$ Edition. New York, John Wiley $\&$ Son Inc.

Loehlin, J.C., (1998). Latent Variable Models: An Introduction to Factor, Path, and Structural Analysis.
Lawrence Erlbaum Associates, Mahwah, NJ 